\title{
Density and Spatial Distribution of Nests of Ectatomma ruidum and Pheidole fallax (Hymenoptera: Formicidae), as Response to the Recovery of Coal Mine Areas
}

\author{
Y DOMINGUEZ-HAYDAR ${ }^{1}$, B GUTIERREZ-RAPALINO ${ }^{1}$, JJ JIMÉNEZ ${ }^{2}$ \\ 1 - Programa de Biología, Facultad de Ciencias Básicas, Universidad del Atlántico, Barranquilla, Colombia \\ 2 - ARAID Researcher, Department of Biodiversity Conservation and Ecosystem Restoration, Pyrenean Institute of Ecology (IPE-CSIC)
}

\section{Article History}

\section{Edited by}

Wesley Dátilo, Department of Eco-Ethology, Instituto de Ecología A.C., Mexico

Received

Initial acceptance

Final acceptance

05 February 2018

07 March 2018

22 June 2018

Publication date

02 October 2018

\section{Keywords}

Mine reclamation, ants, spatial distribution, renewal nest index, Morisita index, nearestneighbor index.

\section{Corresponding author}

Yamileth Dominguez-Haydar

Facultad de Ciencias Básicas

Universidad del Atlántico

Km 7 antigua vía Puerto Colombia

Barranquilla, Colombia.

E-Mail:

yamilethdominguez@mail.uniatlantico.edu.co

\section{Introduction}

The assemblage of ant communities can be structured due to several factors such as vegetation structure and composition, microclimatic conditions, resource provision, altitude, latitude, site heterogeneity, density of nests and intra and interspecific competition (Ryti \& Case, 1984, 1992; Santamaria et al., 2009a). Such factors generate random, aggregated or uniform distribution patterns (Ryti \& Case, 1992), where each one responds to environmental constraints and/or biological interactions between ant colonies (Dillier \& Wehner, 2004; Schatz \& Lachaud, 2008). The spatial distribution of soil organisms is shown to be generally aggregated (clumped) and has shown to be related with heterogeneous habitat and scarce resources (SousaSouto, Viana-Júnior \& Nascimento, 2013). In ants, uniform distribution has been extensively referenced and corresponds to either intra- and interspecific competition (Ryti \& Case, 1992; Redolfi et al., 2005). Random patterns were related to homogeneous conditions, allowing organisms to be located in any available site and, thus, reducing intraspecific competition (Soares \& Schoereder, 2001).

In restored sites, research has focused mainly on ant composition and diversity, leaving aside the distribution patterns of the species, that can be related with microclimate requirements, successional processes, habitat stability and environmental constraints (Holec, Frouz \& Pokorný, 2006). In this study, we selected two species of ants, Ectatomma ruidum (Roger, 1860) and Pheidole fallax (Mayr, 1870) in order to analyze changes in pattern distributions in rehabilitated areas of Cerrejón coal mine (La Guajira, Colombia). DominguezHaydar and Armbrecht (2011) reported that these species 
were the most abundant in the sites with more rehabilitation time and in the forest without mine intervention. The forest surronding the mine is sub-xerophitic, plant species are caducipholy and loose the leaves during dry season. The season is determined by rainfall, two distinct rainfall peaks occur, a light one in April - June, and a heavier one in October - December. This seasonality allows changes in resource availability (Santos, Dáttilo \& Presley, 2014), for this reason, it might change the distribution patterns of ants, which is relevant in restored sites.

We expected that nest density responds to age of rehabilitation. Therefore, nest density in areas with more time of rehabilitation will be more similar to forest than areas at the begining of rehabilitation. Besides, areas with longer rehabilitation time as well as the forest, are more likely than expected by chance (EBC) to show other spatial pattern rather than random distribution. In the present study, we aimed at i) describing the spatial distribution of nests in the restored sites, ii) testing whether there is a relationship between the nest distribution, seasonality and the time after restoration.

\section{Materials and Methods}

Study site

The study was carried out in the Cerrejón coal mine at La Guajira, in northern Colombia $\left(11^{\circ} 3^{\prime} \mathrm{N}, 72^{\circ} 44^{\prime} \mathrm{W}\right.$ $11^{\circ} 8^{\prime} \mathrm{N}, 72^{\circ} 37^{\prime} \mathrm{W}$ ) between 200 and 240 m.a.s.l. (above sea level). The natural ecosystem surrounding the mine is a seasonal dry forest, with vegetation corresponding to subxerophytic and dry forest biotic zones. Precipitation is mainly bimodal (April - June and October - December) with an annual mean of $800 \mathrm{~mm}$, evapotranspiration from 1000 to $1500 \mathrm{~mm}$ (Gualdrón, 2011), and mean annual temperature of $27.5{ }^{\circ} \mathrm{C}$ (isohyperthermy). During the sampling period (2014) a decrease in precipitation $(407 \mathrm{~mm})$ and an increase in evaporation $(2424 \mathrm{~mm}$ ) was observed when compared with the historical trend of the last 10 years (Cerrejón 2014).

The rehabilitation protocol used in the mine consists of three stages: land geomorphological adequacy, topsoil stabilization with grasses (Cenchrus ciliaris $\mathrm{L}$ ) and revegetation with native species (Domínguez-Haydar \& Armbrecht, 2011; Gualdrón, 2011; Domínguez-Haydar et al., 2018).

Due to the high climate variability at the study zone, we carried out two surveys, one in the dry season (March 2014) and the other one at the end of the rainy season (December 2014). We selected three areas with different times since rehabilitation (i.e., one, nine and twenty years old), and another area with a secondary forest not-intervened by mining.

The forest is a compensation area, i.e., it is excluded for future mine use. The tree layer comprised species such as Aspidosperma polyneuron Müll.Arg. and Hura crepitans L. The shrub layer was comprised of Cordia alba (Jacq.) Roem. and Schult., Machaerium sp. and Mimosa arenosa; some exotic African grasses of the genera Andropogon, Brachiaria and Panicum may occasionally be present (Gualdrón, 2011). $1-y$ site have bare soil, dispersed patches of spontaneous grasses. Without revegetation actions and without canopy cover. 9-y site, have high C. ciliaris and tree densities with large canopies $(4-5 \mathrm{~m})$ M. arenosa, A. macracantha, A. tortuosa, Caesalpinia ebano H. Karst. 20-y site have a mosaic of bare soil, some scattered patches of grasses and litter. M. arenosa, A. macracantha, Caesalpinia ébano, P. juliflora, Platymiscium pinnatum (Jacq) Dugand. (Domínguez et al., 2018).

\section{Species description}

Ectatomma ruidum is a hunter ant with omnivorous feeding habits, and individual foraging on litter. The species is widely distributed in Central and South America. They can be found in a wide range of sites, including altered sites by humans (Fernández, 1991).

Pheidole fallax workers are generalist foragers (Roux et al., 2013) with a diet that includes seeds (Lôbo et al., 2011; Gutierrez-Rapalino \& Domínguez-Haydar, 2017) and insects (Jaffe, 1990). have individual foraging, each worker retrieving a small particle of food, and mass recruitment (many individuals cooperating) (Itzkowitz \& Haley, 1983). This ants have Neotropical distribution, i.e., the Greater Antilles, Central America, Colombia, Venezuela and Brazil (Leal, Wirth \& Tabarelli, 2007).

\section{Spatial patterns and nests density}

Obtaining independent areas of the same age of rehabilitation is a typical issue within mining zones. Indeed, pseudoreplication is a common constraint researchers encounter as it is normally present within plots of different years (Davies \& Gray, 2015). However, the large size of the study area (i.e. 20 -y site have 70 ha) made it possible to separate plots for ensuring greater sampling independence. Hence, within each area we established four plots $(6 \times 40 \mathrm{~m})$ with a minimal distance of $300 \mathrm{~m}$ from each other. In each plot we placed 27 tuna baits $(2 \mathrm{~g})$ in a $3 \times 9 \mathrm{~m}$ grid on the soil to localize the nests. The ant workers that approached to the baits were followed to identify the nest entrances, which were pointed with flags. The total number of nests were counted and the distance to the closest nests was measured.

\section{Data analysis}

Nest density: Based on the site type and the sampling season, the nest density of $P$. fallax and $E$. ruidum were compared using the non-parametric Friedman test (with replicated blocked data and chi-square statistics), to compare sampling season, the sites were blocked and for analyzing differences among sites, the sampling season was blocked in the analysis (Srivastava \& Jefferies, 1996; Hollander et al., 2014). Statistical analyses were performed in R (R Development Core Team 2014).

Dispersion pattern: In order to determine how site recovery could affect spatial distribution of ant nests, we performed the Clark and Evans (1954) and Morisita Id (1959) 
aggregation indices in the plots of recovered sites of 9 and 20 years old, as well as within the forest for both ant species. The drawback of using aggregation indices is that the actual spatial location of the nests is not not considered. Thus, it does not provide additional information on the spatial distribution, other than the sampling unit size (Rossi, Lavelle \& Tondoh, 1995). Plot level dispersion was tested with Clark and Evans (1954) nearest-neighbor index (R), this is defined as: $\boldsymbol{R}=\frac{r_{o}}{r_{e}} \boldsymbol{R}=\frac{r_{o}}{r_{e}}, r_{e}=\mathbf{0 . 5} \sqrt{\boldsymbol{D}}$, where $r_{o}$ is the mean of the observed distances between nearest nest and $r_{e}$ is the mean expected, $\mathrm{R}$ ranges from 0 to 2.15 . The $\mathrm{R}$ index value is lower than 1 when the nests exhibit aggregated distribution, it approaches 1 when the distribution of the nests is random, and it is greater than 1 when the distribution is uniform. We evaluated the statistical significance of index values (R) using the standard normal variate $Z$ (Clark \& Evans, 1954), $\boldsymbol{Z}=\left(\boldsymbol{r}_{o}-\boldsymbol{r}_{\boldsymbol{e}}\right) / \boldsymbol{S E Z}=\left(\boldsymbol{r}_{o}-\boldsymbol{r}_{\boldsymbol{e}}\right) / \boldsymbol{S E}$, where $S E$ is the standard error of $r_{e}$, and $\boldsymbol{S E}=\mathbf{0 . 2 6 1 3 6} / \sqrt{\boldsymbol{n d}}$, where $n=$ number of nest and $d$ is nest density. Morisita $I_{d}$ (1959) was used to determine site level dispersion pattern, this index is independent on the sample mean and the total number of individuals in samples, and it is given by: $\boldsymbol{I}_{d}=\boldsymbol{n}\left(\sum_{i=1}^{n}\left(\boldsymbol{x}_{i}{ }^{2}\right)-\sum_{i=1}^{n} \boldsymbol{x}_{i}\right) /\left(\left(\sum_{i=1}^{n} \boldsymbol{x}_{i}\right)^{2}-\sum_{i=1}^{n} \boldsymbol{x}_{i}\right)$ $I_{d}=n\left(\sum_{i=1}^{n}\left(x_{i}^{2}\right)-\sum_{i=1}^{n} x_{i}\right) /\left(\left(\sum_{i=1}^{n} x_{i}\right)^{2}-\sum_{i=1}^{n} x_{i}\right)$, where $\mathrm{n}$ is the number of sampling units (plots); $\mathrm{x}=$ number of nest found in the for the ith sampling unit. $I_{d}$ is equals 1 for random distributions, is less than 1 for regular distributions and greater than 1 for clumped distributions. Departure from randomness can be tested by $Z=\left(I_{d}-1\right) /\left(2 / \mathrm{nm}^{2}\right)^{1 / 2}$, where $\mathrm{m}$ corresponds to the mean of nest, Random spatial distribution will be in case of $1.96 \geq Z \geq-1.96$.
Nest permanence: In order to establish the degree of temporal variation of the number of nests per area, we also calculated both a permanence and a renewal nest index according to Cerdá et al. (2002) and Redolfi et al. (2004). These indices were estimated counting the total number of nests in each sampling; including those that persisted from the previous sampling period.

\section{Results}

Nest density

The number of nests of E. ruidum and P. fallax varied according to sites and sampling season. We found a total of 294 nests, with a range from 0 to 36 nests per plot. E. ruidum had the highest density in rainy season, with 1416.7 nests ha $^{-1}$ in 9-y site, while P. fallax in dry season 583.3 nests ha $^{-1}$ in 20 -y site. We did not find both species E. ruidum and P. fallax in the 1-year site, neither in dry or wet seasons. In the 9-year site, the species were absent just in the dry season (Fig 1).

In general, we observed contrasting differences in the nest density of $P$. fallax and E. ruidum. The density of E. ruidum nests increased during rainy season, mainly in 9-y site (Friedman test, $\mathrm{c}^{2}=7.56, \mathrm{df}=1$, p-value $=0.01$ ). However, we did not find any significant differences among nest density of 9-y, 20-y and the Forest (Friedman test, $c^{2}$ $=1.31, \mathrm{df}=2$, $\mathrm{p}$-value $\mathrm{P}>0.1)($ Fig 1). P. fallax showed significant differences among sites (Friedman test, $\mathrm{c}^{2}=15.5$ $\mathrm{df}=2$, p-value $<0.01$ ), and 20-y site exhibited the highest density of nests, only two nests were found in the forest. For $P$. fallax, there were non-significant differences among seasons (Friedman test, $\mathrm{c}^{2}=1.16, \mathrm{df}=1$, not significant).

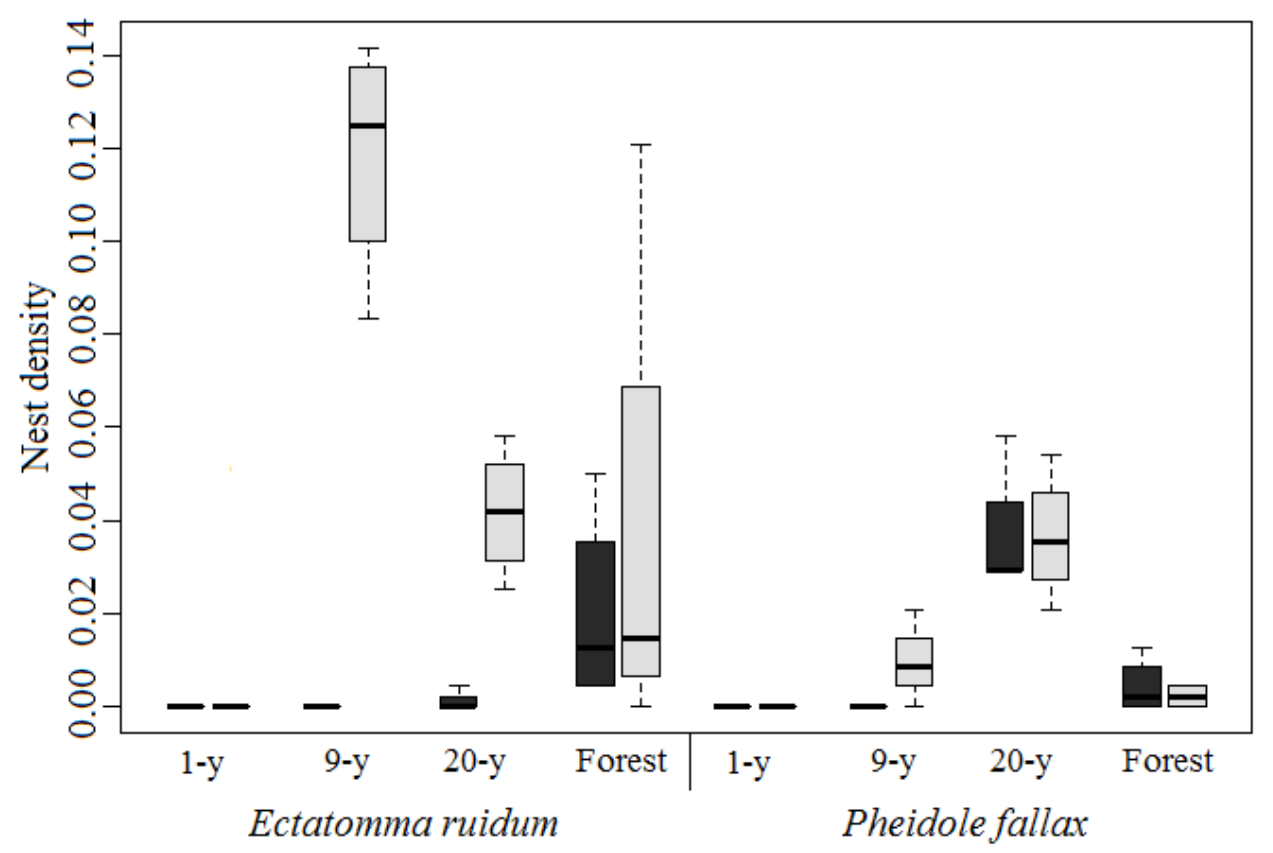

Fig 1. Box-plot of density of nest (Log 10) of E. ruidum and P. fallax in three rehabilitated sites and a forest in "El Cerrejon" mine. Black = Dry season, Gray = Wet season. 
Distribution patterns and temporal permanence of nests

Ants exhibited two types of spatial patterns. At the local scale, Clark and Evans (1954) nearest-neighbor index (R) showed a regular distribution for P. fallax in all sites, except in a plot in forest. While that E. ruidum showed mostly random distributions during wet season, however throughout the dry season the distribution was regular (Table 1). In contrast, to site level Morisita's index showed that $P$. fallax nest were randomly distributed in both seasons and sites while a random distribution was found in the Forest for E. ruidum only (Table 2).

Table 1. Spatial distribution of nest for E. ruidum (E) and P. fallax, (P) at local scale. n: number of nest, R: Clark \& Evans nearestneighbour index, $\mathrm{Z}$ : Test of significance.

\begin{tabular}{|c|c|c|c|c|c|c|c|}
\hline Sites & Plot & $\begin{array}{c}\text { Nearest } \\
\text { neighbor }\end{array}$ & $\mathbf{n}$ & $\mathbf{R}$ & $\mathbf{Z}$ & p-value & Distribution \\
\hline \multicolumn{8}{|c|}{ Dry season } \\
\hline $1-y$ & $1-4$ & - & - & - & - & - & - \\
\hline \multirow[t]{2}{*}{$9-\mathbf{y}$} & $1-4$ & - & - & - & - & - & - \\
\hline & 1 & P-P & 14 & 2.1 & 8.1 & $<0.01$ & Regular \\
\hline \multirow{3}{*}{$20-\mathbf{y}$} & 2 & P-P & 6 & 2 & 4.7 & $<0.01$ & Regular \\
\hline & 3 & P-P & 6 & 2 & 4.6 & $<0.01$ & Regular \\
\hline & 4 & P-P & 6 & 1.8 & 3.75 & $<0.01$ & Regular \\
\hline \multirow{3}{*}{ Forest } & 1 & E-E & 12 & 1.9 & 6.2 & $<0.01$ & Regular \\
\hline & 2 & E-E & 5 & 1.5 & 2.1 & $<0.05$ & Regular \\
\hline & 3 & P-P & 3 & 1 & 0.2 & N.S & Random \\
\hline \multicolumn{8}{|c|}{ Wet season } \\
\hline $1-y$ & $1-4$ & - & - & - & - & - & - \\
\hline \multirow{5}{*}{$9-\mathbf{y}$} & 1 & E-E & 14 & 1.3 & 2.28 & $<0.01$ & Regular \\
\hline & 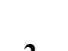 & E-E & 16 & 1.1 & 0.76 & N.S & Random \\
\hline & & P-P & 3 & 1.4 & 3.4 & $<0.01$ & Regular \\
\hline & 3 & E-E & 22 & 1.1 & 0.73 & N.S & Random \\
\hline & 4 & E-E & 22 & 0.9 & -0.24 & N.S & Random \\
\hline \multirow{8}{*}{$20-\mathbf{y}$} & \multirow{2}{*}{1} & P-P & 10 & 1.5 & 2.37 & $<0.01$ & Regular \\
\hline & & E-E & 5 & 0.7 & -0.95 & N.S & Random \\
\hline & \multirow{2}{*}{2} & P-P & 5 & 1.8 & 4.3 & $<0.01$ & Regular \\
\hline & & E-E & 6 & 0.8 & -1 & N.S & Random \\
\hline & \multirow{2}{*}{3} & P-P & 5 & 1.8 & 3.4 & $<0.01$ & Regular \\
\hline & & E-E & 6 & 0.6 & -1.8 & N.S & Aggregated \\
\hline & \multirow{2}{*}{4} & P-P & 3 & 2 & 5.9 & $<0.01$ & Regular \\
\hline & & E-E & 7 & 0.8 & -0.5 & N.S & Random \\
\hline \multirow{2}{*}{ Forest } & 3 & E-E & 18 & 0.21 & -2.5 & $<0.05$ & Aggregated \\
\hline & 4 & E-E & 3 & 1.2 & 1.9 & $<0.05$ & Regular \\
\hline
\end{tabular}

There is a high nest renewal for both species between the dry and rainy seasons, reaching values up to $85 \%$ and $100 \%$ (Table 3). This index was lower in the forest and in $20-y$ site, and highest at 9-y site for both species.

\section{Discussion}

Overall, the density and permanence of $P$. fallax and $E$. ruidum nests responded positively with rehabilitation age in the Cerrejon mine. The presence of these species has been related to areas with high vegetation cover, advanced rehabilitation stages and forest edges (Torres, 1984a; Domínguez-Haydar \&

Table 2. Spatial distribution of nests belonging to E. ruidum (E) and P. fallax, $(\mathrm{P})$ at site scale, according to , Morisita's index (Id). (Z): Test of significance.

\begin{tabular}{|c|c|c|c|c|}
\hline $\begin{array}{l}\text { Climatic } \\
\text { periods }\end{array}$ & Sites & Morisita (Id) & Distribution & $\mathbf{Z}$ \\
\hline \multicolumn{5}{|c|}{ Ectatomma ruidum } \\
\hline \multirow{5}{*}{ Dry season } & $1-y$ & 0.000 & - & - \\
\hline & $9-y$ & 0.000 & - & - \\
\hline & $20-y$ & 0.000 & - & - \\
\hline & Forest & 1.778 & Aggregated & $5.224 *$ \\
\hline & $1-y$ & 0.000 & - & - \\
\hline \multirow{3}{*}{ Wet season } & $9-\mathrm{y}$ & 1.009 & Random & 0.369 \\
\hline & $20-y$ & 1.010 & Random & 0.145 \\
\hline & Forest & 2.635 & Aggregated & $20.809 *$ \\
\hline \multicolumn{5}{|c|}{ Pheidole fallax } \\
\hline \multirow{5}{*}{ Dry season } & $1-y$ & 0.000 & - & - \\
\hline & $9-y$ & 0.000 & - & - \\
\hline & $20-y$ & 1.055 & Random & 0.664 \\
\hline & Forest & 2.000 & Random & 1.414 \\
\hline & $1-y$ & 0.000 & - & - \\
\hline \multirow{3}{*}{ Wet season } & $9-\mathrm{y}$ & 1.333 & Random & 1.061 \\
\hline & $20-y$ & 1.022 & Random & 0.270 \\
\hline & Forest & - & - & - \\
\hline \multicolumn{5}{|c|}{$*$ indicate significant differences $(\mathrm{P}<0.01)$} \\
\hline
\end{tabular}
study site. $\mathrm{TN}=$ Total nests presented in the first sampling; $(\mathrm{RN})$ remaining nest in second sample $1, \mathrm{NN}$ : new nests that appear in sample 2, RMI $=$ Remaining index, $\mathrm{RWI}=$ Renewal index.

\begin{tabular}{clccccc}
\hline Sites & Specie & TN & RN & NN & RMI & RWI \\
\hline \multirow{2}{*}{ 9-y } & E. ruidum & 114 & 0 & 114 & 0 & 100 \\
& P.fallax & 9 & 0 & 9 & 0 & 100 \\
\multirow{2}{*}{ 20-y } & E. ruidum & 40 & 1 & 38 & 2,5 & 95 \\
& P.fallax & 35 & 5 & 30 & 14,3 & 85,7 \\
\multirow{2}{*}{ Forest } & E. ruidum & 36 & 1 & 35 & 2,8 & 97 \\
& P.fallax & 2 & 1 & 1 & 50 & 50 \\
\hline
\end{tabular}


Armbrecht, 2011). Additionally, for the first time, we described the density of $P$. fallax nests for mining areas.

The density of nests found for E. ruidum was consistent with that found by Santamaría et al. (2009a) in a previous study in other areas of the same mine, although, we detected lower nest density in all areas. The density was higher in areas with greater canopy cover and absent in uncovered areas. This also coincided with the absence of this specie in the area under rehabilitation for 1-y. This could be related with climatic differences between both studies. The sampling season had lower precipitation (Cerrejón, 2014) that coincided with dry years of ENSO climatic perturbation (El Niño Southern Oscillation effect). This also would explain the low abundance of $P$. fallax in contrast with a previous study (Domínguez-Haydar \& Armbrecht, 2011) where this ant is abundant in forests.

The permanence of ant nests responded to seasonality, E. ruidum exhibited the major variability. Highest density was found during rainy season, which coincides with the reproductive period of ants, and the establishment of new nests (Levings \& Franks, 1982). From the results of the renewal index, a greater stability is deduced in the forest and in the 20-y site, unlike the 9 -y site showed high variability due to absent of nests during dry season. The native vegetation at "El Cerrejón" mine is principally deciduous, which allows direct light incidence able to increase the soil temperature for up to $45{ }^{\circ} \mathrm{C}$ during the dry season (Domínguez-Haydar, pers. obs.). Thus, we noticed a reduction in the ants activities in those sites with less rehabilitation age and less canopy cover (Domínguez-Haydar \& Armbrecht, 2011). Further, during the dry season resources such as seeds, invertebrates and extrafloral nectaries, which are important items in the diet of E. ruidum were diminished (Passsera, Lachaud \& Gomel, 1993; Santamaría, Armbrecht \& Lachaud, 2009b; Santamaría, Domínguez-Haydar \& Armbrecht, 2009; Gutierrez-Rapalino \& Domínguez-Haydar, 2017). P. fallax accumulate more seeds during dry season that E. ruidum (Gutierrez-Rapalino \& Domínguez-Haydar, 2017). It is possible that this behavior helps to guarantee enough resources to $P$. fallax during dry season, and in consequence, greater permanence.

$P$. fallax and E. ruidum showed different spatial patterns that varied among sites and scale. A comparison between seasons was not possible because the absent of $E$. ruidum in 9-y and 20-y during dry season. A regular pattern was obtained mostly at local scale and for $P$. fallax. A regular distribution pattern is the most common pattern in tropical forests, and is assumed in order to avoid interactions between ant colonies such as intra- and inter-specific competition for space, resources and foraging areas (Ryti \& Case, 1986, 1992; Redolfi et al., 2005). Soldiers of $P$. fallax have been reported in combats (Torres, 1984b), therefore, competition may play an important role at local scale spatial distribution, as demonstrated for other soil invertebrates (Jiménez, Decaëns \& Rossi, 2006). However, for Morisita analyses, random (in rehabilitated areas) and aggregated (in the forest) patterns were found when both species were included in the same analysis, it showed no evidence of interspecific competition. This is a contrasting result, considering that previous studies have documented ecological competition between P. fallax and other species of genus Ectatomma as E. quadridens Smith (1858) (Fowler, 1994). E. quadridens obstructed the nests of $P$. fallax with sand grains, generating a uniform pattern in $P$. fallax. Indicating that larger scales, other constrains different from biological competition are responsible of the spatial pattern observed.

At local scale for E. ruidum, spatial patterns varied according to sites, with regular pattern observed mainly in the forest, while a random distribution prevailed in 9- and 20-y sites. In the latter, this pattern was consistent for both scales and methods (nearest neighbor and $I d$ indices); this random distribution may be related with homogenous and suitable environmental conditions and diminishing of limiting factors as competition (Caldeira et al., 2005; Lörinczi, 2011). The increase in nest density is a response to the suitable conditions present in the restored sites. As demonstrated in other studies, E. ruidum is a successful species in forested areas (Santamaría, Domínguez-Haydar \& Armbrecht, 2009). On the other hand, the high renewal nest found in these sites, could prevent the development of stable competitive relations (Lörinczi, 2011) inducing aggregated or random patterns. However, this result differs from that reported in a previous study where a regular distribution was found at local scale (Santamaría, DomínguezHaydar \& Armbrecht, 2009). It is possible that differences in climatic conditions led to the high variability observed in spatial distribution. In contrast, with the random distribution observed in the 20-y and 9-y sites, an aggregated distribution was found in the forest which is related to higher habitat heterogeneity (Fowler, 1994). Therefore, we hypothesize that changes from random to aggregated patterns between the restored sites and the forest might be either, a response to more complex environmental conditions or an effect of other abiotic variables (as soil temperature and humidity) not analyzed in this study.

Due to the absence of both species in 1-y site, we posit that P. fallax and E. ruidum are indicators of intermediate and advances stage rehabilitation. However, the ant nests density responded to seasonal changes and there was not an increase with the rehabilitation time.

The spatial pattern distributions changed for $P$. fallax in function of scale, whereas in E. ruidum existed an aggregated trend in the forest in both scales. However, we expected a shift from randomness to aggregation in response to more heterogeneous and complex environments, that shows that after 20 years were not yet those of the forest. The use of both indices (Morisita and Clark and Evans) demonstrated this aggregation trend, in particular for E. ruidum. High nest removal led to a redistribution of the nest locations that contributes to seed dispersion in both seasons. In particular, $P$. 
fallax accumulate viable seeds to germinate in nest and refuse piles (Gutierrez-Rapalino \& Domínguez-Haydar, 2017). The emergence of new nests and the abandonment of the oldest also contributes with changes in chemical and physical (i.e. bioturbation) soil properties. Soil heterogeneity is a desired attribute for ecological restoration (Lane \& BassiriRad 2005, Larkin, Vivian-Smith \& Zedler, 2006).

\section{Acknowledgements}

This study was supported by a COLCIENCIAS grant (Colombia), (Code: 1116-569-34827.) and "Vicerrectoría de Investigaciones Extensión y Proyección Social” of Universidad del Atlántico. Particular thanks are extended to "Departamento de Seguridad y Gestión Ambiental" of "Cerrejón” for logistic assistance, to Yair Barros for field assistance, to Dr. Inge Armbrecht for comments on an earlier draft of the manuscript and Soraya Villalobos for revision of the english language.

\section{Authors contribution}

YDH, BGR, JJJ conceived and designed the research; YDH and BGR: collected the data; YDH, BGR, JJJ wrote and edited the manuscript.

\section{References}

Caldeira, M. A., Zanetti, R., Moraes, J.C. \& Zanuncio, J.C. (2005). Distribuição espacial de sauveiros (Hymenoptera: Formicidae) em eucaliptais. Cerne, 11: 34-39. Cerdá, X., Dahbi, A. \& Retana, J. (2002). Spatial patterns, temporal variability, and the role of multi-nest colonies in a monogynous Spanish desert ant, Ecological Entomology. 27: 7-15. doi: 10.1046/j.0307-6946.2001.00386.x.

Clark, P. J. \& Evans, F. C. (1954). Distance to Nearest Neighbor as a Measure of Spatial Relationships in Populations, Ecology. 35: 445-453. doi: 10.2307/1931034.

Davies, G. M. \& Gray, A. (2015). Don't let spurious accusations of pseudoreplication limit our ability to learn from natural experiments (and other messy kinds of ecological monitoring), Ecology and Evolution. 5: 5295-5304. doi: 10.1002/ece3.1782.

Dillier, F. X. \& Wehner, R. (2004). Spatio-temporal patterns of colony distribution in monodomous and polydomous species of North African desert ants, genus Cataglyphis. Insectes Sociaux, 51: 186-196. doi: 10.1007/s00040-003-0722-0.

Domínguez-Haydar, Y. \& Armbrecht, I. (2011). Response of Ants and Their Seed Removal in Rehabilitation Areas and Forests at El Cerrejón Coal Mine in Colombia, Restoration Ecology, 19: 178-184. doi: 10.1111/j.1526-100X.2010.00735.x.

Fernández, F. (1991). Las hormigas cazadoras del género Ectatomma (Formicidae: Ponerinae) en Colombia, Caldasia, 16: 551-564.

Fowler, H. G. (1994). Interference competition between ants (Hymenoptera: Formicidae) in Amazonian clearings. Ecologia Austral, 4: 35-39.

Gualdrón (2011). Hacia la rehabilitación de las tierras intervenidas por la minería a cielo abierto. Colombia. Retrived from: http://www.cerrejon.com/site/Portals/0/Documents/pdf/ Cerrejon - Hacia la rehabiltacion de tierras.pdf.

Gutierrez Rapalino, B. \& Domínguez Haydar, Y. (2017). Contribución de Pheidole fallax y Ectatomma ruidum (Hymenoptera: Formicidae) en la dispersión y germinación de semillas en áreas rehabilitadas de la mina de carbón del Cerrejón, Colombia, Revista de Biología Tropical. 65: 575587. doi: 10.15517/rbt.v65i2.24639.

Holec, M., Frouz, J. \& Pokorný, R. (2006). The influence of different vegetation patches on the spatial distribution of nests and the epigeic activity of ants (Lasius niger) on a spoil dump after brown coal mining (Czech Republic), European Journal of Soil Biology. 42: 158-165. doi: 10.1016/j. ejsobi.2005.12.005.

Itzkowitz, M. \& Haley, M. (1983). The food retrieval tactics of the ant Pheidole fallax Mayr. Insectes Sociaux. SpringerVerlag, 30: 317-322. doi: 10.1007/BF02223989.

Jiménez, J.-J., Decaëns, T. \& Rossi, J.-P. (2006). Stability of the spatio-temporal distribution and niche overlap in neotropical earthworm assemblages. Acta Oecologica, 30: 299-311. doi: 10.1016/j.actao.2006.06.008.

Leal, I. R., Wirth, R. \& Tabarelli, M. (2007). Seed dispersal by ants in the semi-arid Caatinga of north-east Brazil, Annals of Botany. 99: 885-894.

Levings, S. C. \& Franks, N. R. (1982). Patterns of nested dispersion in a tropical ground ant community. Ecology, 63: 338-344. doi: 10.2307/1938951.

Levings, S. C. \& Traniello, J. F. A. (1981). Territoriality, Nest Dispersion, and Community Structure in Ants, Psyche: A Journal of Entomology. 88: 265-319. doi: 10.1155/1981/20795.

Lörinczi, G. (2011). Density and spatial pattern of nests in sub-Mediterranean ground-dwelling ant communities (Hymenoptera: Formicidae), Community Ecology. 12: 51-57. doi: 10.1556/ComEc.12.2011.1.7.

Redolfi, I., Tinaut, A., Pascual, F. \& Campos, M. (2004). Densidad de nidos de la comunidad de hormigas (Formicidae) en tres olivares con diferente manejo agronómico en Granada, España. Ecología Aplicada, 3: 73-81.

Redolfi, I., Ruano, F., Tinaut, A., Pascual, F. \& Campos, M. (2005). Distribución espacial y permanencia temporal de hormigueros en el agrosistema del olivo en Granada, España, Ecología Aplicada, 4: 71-76.

Rossi, J.-P., Lavelle, P. \& Tondoh, J. E. (1995). Statistical tool for soil biology. X. Geostatistical analysis, European Journal of Soil Biology, 31: 173-181. 
Ryti, R. T. \& Case, T. J. (1984). Spatial arrangement and diet overlap between colonies of desert ants, Oecologia. 62: 401-404.

Ryti, R. T. \& Case, T. J. (1986). Overdispersion of ant colonies: a test of hypotheses, Oecologia. 69: 446-453. doi: 10.1007/BF00377067.

Ryti, R. T. \& Case, T. J. (1992). The Role of Neighborhood Competition in the Spacing and Diversity of Ant Communities. The American Naturalist, 139: 355-374.

Santamaría, C., Armbrecht, I. \& Lachaud, J.-P. (2009). Nest Distribution and Food Preferences of Ectatomma ruidum (Hymenoptera: Formicidae) in Shaded and Open Cattle Pastures of Colombia. Sociobiology, 53: 517-541.

Santamaría, C., Domínguez-Haydar, Y. \& Armbrecht, I. (2009). Cambios en la distribución de nidos y abundancia de la hormiga Ectatomma ruidum (Roger 1861) en dos zonas de Colombia, Boletín del Museo de Entomología de la Universidad del Valle, 10: 10-18.
Soares, S. M. \& Schoereder, J. H. (2001). Ant-nest distribution in a remnant of tropical rainforest in southeastern Brazil. Insectes Sociaux, 48: 280-286. doi: 10.1007/PL00001778.

Sousa-Souto, L., Viana Junior, A. B. \& Nascimento, E. S. (2013). Spatial Distribution of Acromyrmex balzani (Emery) (Hymenoptera: Formicidae: Attini) Nests Using Two Sampling Methods. Sociobiology, 60: 162-168. doi: 10.13102/sociobiology.v60i2.162-168.

Srivastava, D. S. \& Vellend, M. (2005). BiodiversityEcosystem Function Research: Is It Relevant to Conservation? Annual Review of Ecology, Evolution, and Systematics, 36: 267-294. doi: 10.1146/annurev.ecolsys.36.102003.152636.

Torres, J. A. (1984a). Diversity and distribution of ant communities in Puerto Rico. Biotropica, 16: 296-303. doi: $10.2307 / 2387938$.

Torres, J. A. (1984b). Niches and coexistence of ant communities in Puerto Rico: repeated patterns, Biotropica. 16: 284-295. doi: 10.2307/2387937. 